\title{
Pulmonary hypertension: have we learned enough yet?
}

\author{
Davide Cattano $\cdot$ Marie Francoise Doursout
}

Received: 29 June 2012/ Accepted: 4 August 2012/Published online: 18 August 2012

(C) SIMI 2012

["when you are a child you want to be like your father, as you grow to be a teenager you want to be anything except your father, and then as a man you realize that you are your father"]

(Adapted from Charles Farmer quote, Farmer the Astronaut)

Pulmonary arterial hypertension (PAH) is a lifethreatening, vascular proliferative disease of the lung, which is characterized by vasoconstriction and remodeling of small pulmonary arteries. Consequently, PAH is characterized by an increase in mean pulmonary arterial pressure (mPAP $>25 \mathrm{mmHg}$ ) with limited treatment options and poor prognosis $[1,2]$. Specifically, the disorder causes right ventricular hypertrophy and can quickly lead to death, especially with the severe forms of pulmonary hypertension.

In the United States (USA), PAH affects an estimated two to three times as many women as men. PAH usually develops between 20 and 60 years of age; however, it can occur at any age. According to Centers for Disease Control and Prevention (CDC) statistics, between 2000 and 2002, 807,000 patients were hospitalized with $\mathrm{PH} ; 61 \%$ were female, and $66 \%$ were 65 years or older. Statistics from the CDC also report that PAH led to 15,688 deaths and 260,000 hospitalizations in 2002. Prior to 1995, individuals with PAH live, on average, less than 3 years after diagnosis; however, with emerging therapies, survival rates and quality of life for those living with this condition have improved [3]. Despite large advances in the last 10 years,

D. Cattano $(\bowtie) \cdot$ M. F. Doursout

Department of Anesthesiology, The University of Texas,

Medical School at Houston, Houston, TX, USA

e-mail: davide.cattano@uth.tmc.edu there is still about a $15 \%$ annual mortality for diagnosed patients in the US.

Recent strategies have shown promise in animal models to prevent the onset of pulmonary hypertension when it is induced. As such, over the past decades, a large number of experimental animal models of PAH have been developed, and mainly rely on hypoxic or monocrotaline injected rodents; the creation of left to right shunts in lambs or piglets, and the ligation of the ductus arteriosus in newborn lambs [4]. While none of the models have yet reproduced $\mathrm{PAH}$, each allows investigation of a specific hypothesis.

More recently, an increasing number of genetically manipulated rodents and tissue cultures are becoming available for the investigation of specific signaling pathways, resulting in recent molecular and cellular approaches [5]. Consequently, animal models of PAH that share basic biological abnormalities, which, together with the study of lung tissue from patients with severe diseases have led to a better understanding of the pathology and therapeutic innovation. As a result, current therapies include endothelin receptor antagonists, prostacyclin agonists, and cGMP-specific 3', 5'-cyclic phosphodiesterase (PDE5) inhibitors [6].

In a recent study, Grimminger and Schermuly [7] have investigated the development of a causal treatment aiming at normalization of the vessel wall structure. The authors have investigated new non-vasoactive drugs in relevant preclinical animal models of PAH. Some substances such as tyrosine kinase inhibitors, elastase inhibitors, and phosphodiesterase-1-inhibitors can not only attenuate (antiremodeling) but also reverse (reverse-remodeling) the disease. Although these treatments are largely used, there is current controversy regarding whether vasoconstriction plays a significant role in the elevated pressure of severe, advanced stages of PAH. Oka et al. [8] observe that Rhokinase inhibitors, a novel class of potent vasodilators, 
reduce the high pulmonary artery pressure of major animal models of PAH acutely, suggesting that vasoconstriction can significantly be involved in pulmonary hypertension with severely remodeled (occluded) pulmonary vessels. Additionally, new vasodilators such as soluble guanylate cyclase stimulators and activators, addressing well-known and new signaling pathways are currently under investigation $[9,10]$.

Interestingly, in rats subjected to monocrotaline (mCT)induced PAH, Kamezaki et al. [11] suggest that extracellular superoxide dismutase (EC-SOD) may act as an antioxidant in $\mathrm{PAH}$, and that increased oxidative stress may be important in the pathogenesis of monocrotaline-induced PAH. Thus far, the pathogenesis of PAH is dominated by a significant increase of pulmonary resistance due to cellular and biochemical modifications that lead to endothelial dysfunction, vasoconstriction, arterial wall thickening, and thrombosis.

Presently, besides current vasoactive drugs, novel therapeutic options are under development. Gene microarray technology has successfully been used in the investigation of a diverse array of human diseases. The potential of highthroughput expression analysis to improve our understanding of the pathogenesis of PAH is clear [12]. Although many studies to date, specifically in cancer, have used microarray analysis as a hypothesis-generating tool, this technology also has vast potential as a means of identifying and quantifying biomarkers of disease. It is likely that, in the near future, gene microarray analyses will also be used in a pharmacogenomics approach in PAH, helping to identify the most appropriate therapies for individual patients [13]. These goals are ambitious, but certainly achievable. Such approaches will significantly increase our understanding of the pathobiology of PAH and aid in our struggle against this disabling and deadly disease. Although Giaid et al. [14] and Yamanaka et al. [15] report that endothelin-1 has an important role in vasoconstriction and increased plasma levels have been found in $\mathrm{PAH}$, these findings prompted Calabrò et al. [16] to analyze the frequency and the potential role of 2 polymorphisms in a cohort of 98 patients with PAH and 100 healthy subjects randomly recruited.

In this meaningful study, published in the present issue of the journal, the authors report the potential link between specific genotypes in the endothelin receptor type A (EDNRA) gene and susceptibility for PAH with a worse hemodynamic profile. The work from Calabrò et al. [16] updates a common and biologically sound concept into a translational investigation, dissecting the endothelin-1 axis, through a simple observational case control study. The cohort of almost 200 patients (age-matched control and experimental) makes the study one well populated of its kind, although the diversity of the patients' condition groups limits the investigations power. Besides the fact that Calabro's study and previous experimental and clinical studies [17, 18] suggest a potential role of EDNRA polymorphisms in the pathophysiology of PAH, the main limitation of the present study is the lack of demonstration of an experimental (in vitro and in vivo) functional role for this genotype. In addition to EDNRA polymorphism, there is some evidence that serotonin transporter gene polymorphism is a determinant of severity of pulmonary hypertension.

Concisely, the pathogenesis of PAH is incompletely characterized, but it is likely to be multifactorial involving the interaction between the genetic background and the environment of the individual. Taken together, with increasing insight into the pathology of PAH, several novel drug targets and treatments have emerged that may improve the management of patients and whose efficacy is currently addressed in preclinical studies and clinical trials.

Development of molecules that target pathophysiological abnormalities should be the goal of future research. This issue has not been addressed even experimentally, due mainly to a lack of appropriate animal models. The science base for the etiology, pathogenesis, and complications of pulmonary hypertension disease entities must be further investigated to improve prevention, treatment, and case management. Although multiple predisposing factors and associated conditions have been identified for PAH, additional epidemiologic initiatives are also needed to ascertain the prevalence and incidence of the various disease entities.

Conflict of interest None to be declared.

\section{References}

1. Sastry BK, McGoon MD, Gibbs JS (2010) Clinical trials for pulmonary hypertension in the developing world: pulmonary vascular disease: the global perspective. Chest 137(6 Suppl):62S$68 \mathrm{~S}$

2. Badesch DB, Champion HC, Sanchez MA, Hoeper MM, Loyd JE, Manes A, McGoon M, Naeije R, Olschewski H, Oudiz RJ, Torbicki A (2009) Diagnosis and assessment of pulmonary arterial hypertension. J Am Coll Cardiol 54(1 Suppl):S55-S66

3. Terrie YC (2010) Pulmonary arterial hypertension: keeping patients informed. Pharmacy Times (published online: December 13). http://www.pharmacytimes.com/publications/issue/2010/December 2010/Counseling-1210

4. Naeije R, Dewachter L (2007) [Animal models of pulmonary arterial hypertension]. Rev Mal Respir 24(4 Pt 1):481-496

5. Austin ED, Loyd JE (2007) Genetics and mediators in pulmonary arterial hypertension. Clin Chest Med 28(1):43-57

6. Greenway S, van Suylen RJ, Du Marchie Sarvaas G, Kwan E, Ambartsumian N, Lukanidin E, Rabinovitch M (2004) S100A4/ Mts1 produces murine pulmonary artery changes resembling plexogenic arteriopathy and is increased in human plexogenic arteriopathy. Am J Pathol 164(1):253-262 
7. Grimminger F, Schermuly RT (2010) PDGF receptor and its antagonists: role in treatment of PAH. Adv Exp Med Biol 661:435-446

8. Oka M, Homma N, McMurtry IF (2008) Rho kinase-mediated vasoconstriction in rat models of pulmonary hypertension. Methods Enzymol 439:191-204

9. Schermuly RT, Stasch JP, Pullamsetti SS, Middendorff R, Müller D, Schlüter KD, Dingendorf A, Hackemack S, Kolosionek E, Kaulen C, Dumitrascu R, Weissmann N, Mittendorf J, Klepetko W, Seeger W, Ghofrani HA, Grimminger F (2008) Expression and function of soluble guanylate cyclase in pulmonary arterial hypertension. Eur Respir J 32(4):881-891

10. Weissmann N, Hackemack S, Dahal BK, Pullamsetti SS, Savai R, Mittal M, Fuchs B, Medebach T, Dumitrascu R, Eickels M, Ghofrani HA, Seeger W, Grimminger F, Schermuly RT (2009) The soluble guanylate cyclase activator HMR1766 reverses hypoxia-induced experimental pulmonary hypertension in mice. Am J Physiol Lung Cell Mol Physiol 297(4):L658-L665

11. Kamezaki F, Tasaki H, Yamashita K, Tsutsui M, Koide S, Nakata S, Tanimoto A, Okazaki M, Sasaguri Y, Adachi T, Otsuji Y (2008) Gene transfer of extracellular superoxide dismutase ameliorates pulmonary hypertension in rats. Am J Respir Crit Care Med 177(2):219-226

12. Bull TM, Coldren CD, Geraci MW, Voelkel NF (2007) Gene expression profiling in pulmonary hypertension. Proc Am Thorac Soc 4(1):117-120
13. Woodcock J (2005) Pharmacogenetics: on the road to 'personalized medicine'. FDA Consum 39(6):44

14. Giaid A, Yanagisawa M, Langleben D, Michel RP, Levy R, Shennib H, Kimura S, Masaki T, Duguid WP, Stewart DJ (1993) Expression of endothelin-1 in the lungs of patients with pulmonary hypertension. N Engl J Med 328(24):1732-1739

15. Yamanaka R, Otsuka F, Nakamura K, Yamashita M, Otani H, Takeda M, Matsumoto Y, Kusano KF, Ito H, Makino H (2010) Involvement of the bone morphogenetic protein system in endothelin- and aldosterone-induced cell proliferation of pulmonary arterial smooth muscle cells isolated from human patients with pulmonary arterial hypertension. Hypertens Res 33(5): 435-445

16. Calabrò $\mathrm{P}$, Limongelli G, Maddaloni V, Vizza CD, D'Alto $\mathrm{M}$, D'Alessandro R, Poscia R, Argiento P, Ziello B, Badagliacca R, Romeo E, Pacileo G, Russo MG,Fedele F, Calabrò R (2011) Analysis of endothelin-1 and endothelin-1 receptor A gene polymorphisms in patients with pulmonary arterial hypertension. Intern Emerg Med. doi:10.1007/s11739-011-0643-2

17. Schiffrin EL, Deng LY, Sventek P, Day R (1997) Enhanced expression of endothelin-1 gene in resistance arteries in severe human essential hypertension. J Hypertens 15(1):57-63

18. Hirata Y, Yoshimi H, Takaichi S, Yanagisawa M, Masaki T (1988) Binding and receptor down-regulation of a novel vasoconstrictor endothelin in cultured rat vascular smooth muscle cells. FEBS Lett 239(1):13-17 